\title{
Perception of castration value over cost in the metastatic prostate cancer scenario: a contemporary pharmacoeconomic perspective
}

Luciana Saboya Brito Dal Col 1,2, Danilo L. Andrade "1, Lucas M. Gon 1, Diego M. Capibaribe ${ }^{1}$, Marcelo P. Amaro ${ }^{1,2}$, Natássia C. C. Truzzi ${ }^{1}$, Barbara R. Malkomes ${ }^{1,2}$, Leonardo 0. Reis ${ }^{1,2}$

${ }^{1}$ UroScience, Universidade Estadual de Campinas - UNICAMP, Campinas, SP, Brasil; ${ }^{2}$ Departamento de Urologia, Pontifícia Universidade Católica de Campinas - PUC - Campinas, Campinas, SP, Brasil

\section{INTRODUCTION}

Prostate cancer is the most prevalent cancer in the male population, and although it may have a mainly indolent course, it can also progress to metastatic cancer, which has a median survival of 42 months (1-3).

The first line of treatment for metastatic prostate cancer aims to eliminate testosterone's stimulatory effect (4) and inhibit disease progression. Both surgical and pharmacological approaches can achieve testosterone castration levels. With appropriate treatment, men with prostate cancer can live longer, making it necessary to minimize the risks of harm, considering general health, sexuality, psychological, and economic effects in the long term $(5,6)$.

Financial toxicity is an exponentially growing concern as it directly influences the quality of life and treatment adherence, culminating with wasted resources, and suboptimal clinical outcomes.

However, about one-third of the oncologists express a high degree of discomfort discussing costs with patients (7-11) and both caregivers and patients avoid discussing cost-related issues due to factors such as potential bias to treatment recom- mendations. In metastatic prostate cancer disease, urologists play an essential role in helping patients decide the best treatment. It is crucial to consider the treatment's economic impact, beyond clinical factors, patient desires, and expectations.

To further understand the underuse of surgical castration (12) even among urologists, we consecutively and anonymously interviewed one hundred urologists during a urology meeting. They answered a survey with multiple-choice questions regarding their perceptions of value, cost, and pharmacoeconomic issues concerning metastatic prostate cancer castration treatment.

\section{MATERIALS AND METHODS}

Briefly, a questionnaire assessed the environment of practice (public, private, or academic) and the country region. The urologists were asked whether they treated patients with metastatic prostate cancer, and the current percentage for chemical or surgical castration use, totalizing 100\%. Also, if the remuneration for the surgical castration were ten times higher than it is, how would this percentage change, and the three main reasons for choosing medical castration. The next question asked: 
by opting for surgical castration, how many avoided pharmacological castrations could save enough resources for one patient to have access to a second-generation antiandrogen.

ANOVA compared repeated measures by means across one or more variables, and the Cohen test measured the effect size using the SAS System for Windows (Statistical Analysis System), 9.4 version, SAS Institute Inc, Cary, NC, USA.

\section{RESULTS}

Among one hundred urologists screened for the study, 34 either did not treat prostate cancer routinely or refrained from participating. Among the participants, 37.8\% had more than 15 years of practice, and $21.2 \%$ worked in an academic center.

Pharmacological castration is regularly offered for 78.05\% of patients (mean, SD 28.06, median 90\%); 62.5\% in academic versus $82.2 \%$ in non-academic centers, $p=018$. That rate would drop significantly to $54.21 \%$ (mean, SD 38.88 , median 50.00\%, p <0.0001), a major effect (0.88) on Cohen's test, if money compensation for the procedure would increase 10-fold.

Those that considered surgical castration cost-effective (60.6\%), are significantly more susceptible to financial incentives $(p=0.036)$. In contrast, those who usually choose pharmacological castration due to convenience, remuneration, and modernity are considerably less susceptible $(\mathrm{p}=0.044)$.

When asked about the number of surgical castrations needed to save enough money to provide one patient with access to a second-generation antiandrogen the answers were: the rationale is not valid by $n=23$ (34.85\%), $5-15$ by $n=29$ (43.93\%), and $16-25$ by $n=14$ (21.21\%) urologists.

\section{DISCUSSION}

Financial toxicity can be as devastating as other adverse medical events, causing patient distress, morbidity and mortality. Surgical castration can be significantly less expensive than pharmacological with similar oncological and functional impact (13).
However, chemical castration is still the preferred choice, even for patients who need lifelong androgen deprivation therapy (14). The current study shows that it is regularly offered for 78.05\% of patients (mean, SD 28.06, median $90 \%$ ); $62.5 \%$ in academic versus $82.2 \%$ in non-academic centers, $\mathrm{p}=018$.

Urologists infrequently offered patients a choice or considered patient's beliefs and preferences, implying limited patient participation in the management of their care as previously reported (15). By not offering choice, the opportunity for a shared decision making is hampered. On the other hand, the percentage of pharmacological castration offered would significantly drop if surgical castration was best remunerated. This could be one reason why many urologists still choose pharmacological treatment over orchiectomy, considering the significant influence of pharmaceutical industries in this specific field, while surgical treatment is still inadequately compensated.

Surgical and pharmacological castration has shown similar oncological results. Still, men are supposedly more prone to refuse orchiectomy based on the cosmetics and psychological factors regarding self-image and its irreversibility.

Though controversial, according to Sun et al. (13), pharmacological castration was associated with significantly higher risks of fractures, peripheral arterial disease, diabetes mellitus, and cardiac-related complications when compared to surgery. Bonzani et al. (16) have found no difference when comparing the quality of life and body image among medically and surgically castrated patients. Potosky et al. (17) showed that men were more likely to worry about their disease and overall health with treatment, reinforcing the importance of considering long-term implications including costs while choosing between surgical or pharmacological treatment.

Orchiectomy is highly effective, outpatient surgery, low cost, low morbidity, and the treatment is warranted essentially in case of drug shortage, financial issues, or patient non-adherence to the treatment. One must also consider that surgery can achieve castration levels faster than medication, and it is not vulnerable to patient adherence or medication availability. Nonetheless, it still suffers 
massive critic from the interested parties. It is easy to realize that a simple tactic such as improving the medical compensation for surgical castration and also including a testicular prosthesis to the "orchiectomy kit" would convert it to a significant overall economy and patient benefit $(18,19)$.

The costs and resources of public and private health care are discrepant. In the public system in Brazil, a subcapsular orchiectomy outpatient surgery costs the government (at a lifetime) on average USD 83.00 (R\$ 453.62) while chemical castration per year costs USD 950.00 ( $\mathrm{R} \$ 5.200 .00$ ), not considering treatment of eventual surgical complications or medication side effects (20). In many places, the government does not provide the medicine being this cost passed on to the patient or generating legal processes that further increase spending.

One patient at chemical castration spends money enough to treat about 11 patients with surgical castration in a year and 57 patients in 5 years (Figure-1). From a different perspective, offering surgical castration to 30 patients (in opposition to chemical) will save money enough to treat at least 1 castration-resistant patient with second-generation antiandrogen for a lifetime. While numbers might vary, the cost-effective trend for surgical castration is time sensible and exponential.

Though the potential reversibility is considered a central argument favoring the pharmacological castration, it is theoretical once the hypothalamic-testicle axis takes months or years to awake from chronic inhibition and testosterone replacement warrants an immediate, effective, cheap and safe recover in body composition, lipid parameters, and quality of life $(21,22)$.

Another subject of interest is the potential effect of drug interactions considering that many patients have comorbidities and face polypharmacy (23). In the metastatic non-curable disease scenario, the surgical castration irreversibility is not an issue, and it can save money for sequential treatments once financial burden impacts not only the individual but also the overall healthcare system.

As a random consecutive interview during a national congress, our study reflects a sample from the Brazilian urology community. It may not represent the whole community view, but it can point out some directions for further studies and awareness actions, like cost-effectiveness in uro-oncology and strategies to encourage treatment modifications.

\section{Figure 1 - Number of patients treated with same investment comparing surgical and pharmacological castration (20).}

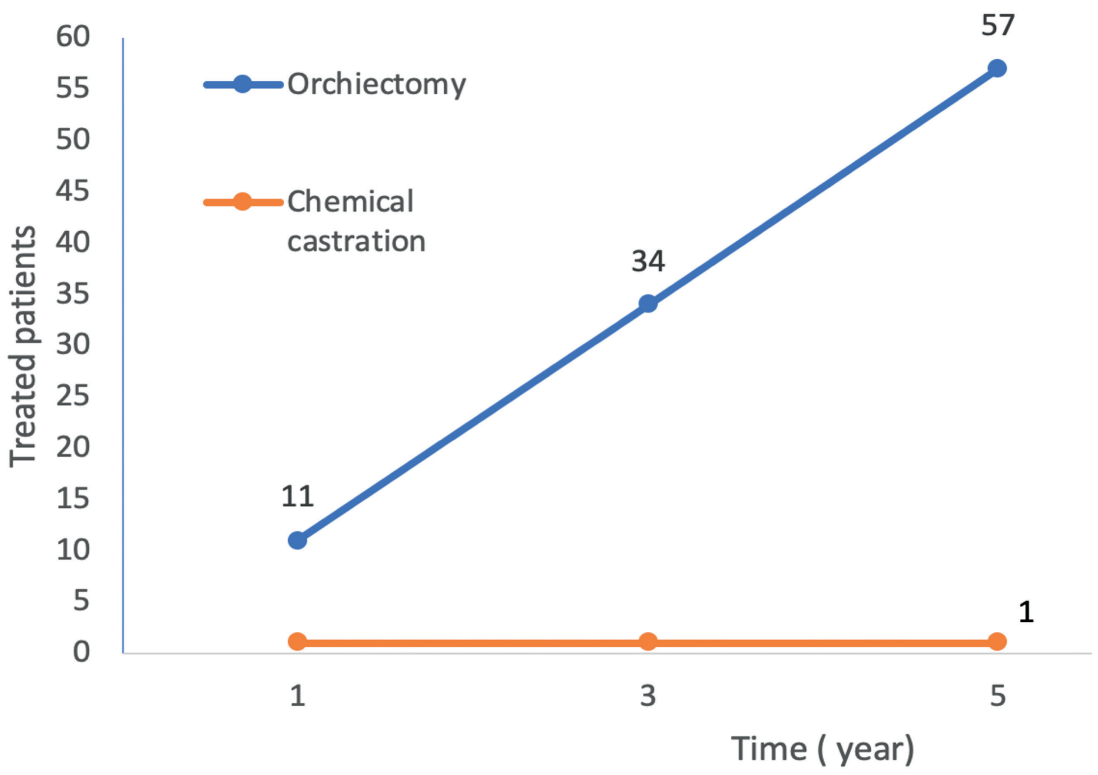


It is remarkable the coercion power of the medical device and pharmaceutical industry in medical behaviors. Improve medical remuneration can provide the best oncological outcome for the patient and the community. Moreover, most of the doctors have limited pharmacoeconomic knowledge, which is necessary to support the decisions and discussion with patients.

Pharmacological castration is still the preferred therapy among urologists when it comes to metastatic prostate cancer, despite having similar oncological results, higher costs, and potential for more collateral effects than orchiectomy. The described study results showed that the urology community is sensible to the fact that cost is not necessarily translated to value in this scenario. The pharmacoeconomic awareness is fundamental and should enlighten discussions concerning metastatic prostate cancer treatment in both public and private sectors, in addition to adapting the reality of medical conduct in a developing country that struggles to provide free health care to the entire population.

An unbiased patient centered decision is vital in the contemporary treatment landscape of castration resistant prostate cancer and additional strategies to improve patient care and fight financial toxicity beyond the surgical castration value perception might involve bipolar androgen therapy with potential to enhance quality of life, prolong disease stabilisation, postpone and improve the magnitude and duration of response to second-generation antiandrogens to maximise therapeutic benefit to patients (24).

\section{CONFLICT OF INTEREST}

None declared.

\section{REFERENCES}

1. Miller KD, Siegel RL, Lin CC, Mariotto AB, Kramer JL, Rowland $\mathrm{JH}$, et al. Cancer treatment and survivorship statistics, 2016. CA Cancer J Clin. 2016; 66:271-89.

2. Litwin MS, Tan HJ. The Diagnosis and Treatment of Prostate Cancer: A Review. JAMA. 2017; 317:2532-42.
3. James ND, Spears MR, Clarke NW, Dearnaley DP, De Bono JS, Gale J, et al. Survival with Newly Diagnosed Metastatic Prostate Cancer in the "Docetaxel Era": Data from 917 Patients in the Control Arm of the STAMPEDE Trial (MRC PR08, CRUK/06/019). Eur Urol. 2015; 67:1028-38.

4. Cornford P, Bellmunt J, Bolla M, Briers E, De Santis M, Gross T, et al. EAU-ESTRO-SIOG Guidelines on Prostate Cancer. Part II: Treatment of Relapsing, Metastatic, and CastrationResistant Prostate Cancer. Eur Urol. 2017; 71:630-42.

5. Kolinsky M, Rescigno P, de Bono JS. Chemical or Surgical Castration--Is This Still an Important Question? JAMA Oncol. 2016; 2:437-8.

6. Sasse AD, Dos Reis RB, Nogueira LM, Maluf FC, Herchenhorn D, Smaletz 0, et al. Second brazilian consensus on the treatment of advanced prostate cancer - a SBOC-SBU-SBRT panel review. Int Braz J Urol. 2019; 45:449-58.

7. Zafar SY, Peppercorn JM, Schrag D, Taylor DH, Goetzinger AM, Zhong $X$, et al. The financial toxicity of cancer treatment: a pilot study assessing out-of-pocket expenses and the insured cancer patient's experience. Oncologist. 2013; 18:381-90.

8. Shankaran V, Jolly S, Blough D, Ramsey SD. Risk factors for financial hardship in patients receiving adjuvant chemotherapy for colon cancer: a population-based exploratory analysis. J Clin Oncol. 2012; 30:1608-14.

9. Jagsi R, Pottow JA, Griffith KA, Bradley C, Hamilton AS, Graff J, et al. Long-term financial burden of breast cancer: experiences of a diverse cohort of survivors identified through population-based registries. J Clin Oncol. 2014; 32:1269-76.

10. Khera N, Chang YH, Hashmi S, Slack J, Beebe T, Roy V, et al. Financial burden in recipients of allogeneic hematopoietic cell transplantation. Biol Blood Marrow Transplant. 2014; 20:1375-81.

11. Mossanen M, Smith $A B$. Addressing Financial Toxicity: The Role of the Urologist. J Urol. 2018; 200:43-5.

12. de Freitas CSM, Soares AN. Efficacy of Leuprorelide acetate (Eligard $\left.{ }^{\circledR}\right)$ in daily practice in Brazil: a retrospective study with depot formulations in patients with prostate cancer. Int Braz J Urol. 2020; 46:383-9.

13. Sun M, Choueiri TK, Hamnvik OP, Preston MA, De Velasco $G$, Jiang W, et al. Comparison of Gonadotropin-Releasing Hormone Agonists and Orchiectomy: Effects of AndrogenDeprivation Therapy. JAMA Oncol. 2016; 2:500-7.

14. Krahn M, Bremner KE, Tomlinson G, Luo J, Ritvo P, Naglie $G$, et al. Androgen deprivation therapy in prostate cancer: are rising concerns leading to falling use? BJU Int. 2011; 108:1588-96.

15. Pieterse AH, Henselmans I, de Haes HC, Koning CC, Geijsen ED, Smets EM. Shared decision making: prostate cancer patients' appraisal of treatment alternatives and oncologists' eliciting and responding behavior, an explorative study. Patient Educ Couns. 2011; 85:e251-9. 
16. Bonzani R, Stricker J, Peabody J. Quality of life comparison of lupron and orchiectomy. J Urol. 1996; 155(suppl):611A.

17. Potosky AL, Knopf K, Clegg LX, Albertsen PC, Stanford JL, Hamilton AS, et al. Quality-of-life outcomes after primary androgen deprivation therapy: results from the Prostate Cancer Outcomes Study. J Clin Oncol. 2001; 19:3750-7.

18. Weiner AB, Cohen JE, DeLancey JO, Schaeffer EM, Auffenberg GB. Surgical versus Medical Castration for Metastatic Prostate Cancer: Use and Overall Survival in a National Cohort. J Urol. 2020; 203:933-9.

19. Johnstone GP, Johnstone PAS. The Oncologist's Role in Managing Financial Toxicity. Int J Radiat Oncol Biol Phys. 2018; 101:306-8.

20. [No Authors]. Sistema de Gerenciamento da Tabela de Procedimentos, Medicamentos e OPM do SUS - SIGTAP. Ministério da Saúde. DATASUS. [Internet]. 2020. Available at. <http://sigtap.datasus.gov.br/tabela-unificada/app/sec/ procedimento/exibir/0409040142/01/2021>.
21. Ferreira U, Leitao VA, Denardi F, Matheus WE, Stopiglia RM, Netto NR Jr. Intermittent androgen replacement for intense hypogonadism symptoms in castrated patients. Prostate Cancer Prostatic Dis. 2006; 9:39-41.

22. Marshall CH, Tunacao J, Danda V, Tsai HL, Barber J, Gawande $R$, et al. Reversing the effects of androgen-deprivation therapy in men with metastatic castration-resistant prostate cancer. BJU Int. 2021:Mar(26). Online ahead of print.

23. Reis LO, Dal Col LSB, Sadi MV. National Consensus on Nonmetastatic Castration-Resistant Prostate Cancer: more than just a snapshot. Int Braz J Urol. 2021; 47:374-7.

24. Denmeade SR, Wang H, Agarwal N, Smith DC, Schweizer MT, Stein MN, et al. TRANSFORMER: A Randomized Phase II Study Comparing Bipolar Androgen Therapy Versus Enzalutamide in Asymptomatic Men With Castration-Resistant Metastatic Prostate Cancer. J Clin Oncol. 2021; 39:1371-1382.

Leonardo O. Reis, MD, MSc, PhD

UroScience, Universidade Estadual de Campinas UNICAMP

Av. John Boyd Dunlop, Jardim Ipaussurama

Campinas, São Paulo, SP, 13034-685, Brasil

Telephone: +55 19 3343-8600

E-mail: reisleo.l@gmail.com

ARTICLE INFO

Reis $L O$

http://orcid.org/0000-0003-2092-414X

Int Braz J Urol. 2022; 48: 175-9

\begin{tabular}{r}
$\begin{array}{r}\text { Submitted for publication: } \\
\text { March 31, } 2021\end{array}$ \\
Accepted after revision: \\
April 10, 2021 \\
\hline Published as Ahead of Print: \\
June 15, 2021
\end{tabular}

